\title{
Radical Cystectomy with Orthotopic Neobladder for Invasive Bladder Cancer: A Critical Analysis of Long Term Oncological, Functional and Quality of Life Results
}

\author{
Arnulf Stenzl, Hammouda Sherif, Markus Kuczyk \\ Department of Urology, University of Tuebingen, Tuebingen, Germany
}

\begin{abstract}
Purpose: Analyze current knowledge and practice regarding tumor-related cystectomy with subsequent orthotopic neobladder both in male and female patients.

Design, setting, and participants: Evaluate literature predominantly from the last decade dealing with long-term experience in large numbers of patients with an orthotopic neobladder following cystectomy. Oncological outcome specific to an orthotopic neobladder, functional aspects such as urinary continence, renal function, sexual activity and other quality of life issues are elucidated.

Results: Local pelvic recurrences after urothelial bladder cancer occur in 7-12\%. Urethral second primary tumors in male and female patients in contemporary series with bladder substitution are 4-6\% and 1.4 o 4\%, respectively. Upper tract recurrences vary between $2.4-17 \%$. Complications regarding the upper urinary tract have dramatically diminished due to simplified forms of upper tract protection as well as a more refined technique of ureterointestinal anastomosis. Depending on the technique ureteroileal stenosis was lately reported to lie between 2.7 to $3.8 \%$. Renal function remained stable in $96 \%$ after a mean follow-up of up to 5 years.

Conclusion: Radical cystectomy in carefully selected patients has stood the test of time by providing adequate long-term survival and low local recurrence rates. Orthotopic bladder substitution does not compromise oncological outcome, yields excellent functional results, is cost effective compared to other types of urinary diversion, may improve quality of life and should therefore be the diversion of choice both in men and women. Chronological age is generally not a contraindication for cystectomy, but for orthotopic urinary diversion, tumor extent, functional pelvic floor deficits and general life expectancy are limiting factors.
\end{abstract}

Key words: bladder neoplasms; cystectomy; urinary diversion; quality of life, oncology

Int Braz J Urol. 2010; 36: 537-47

\section{INTRODUCTION}

Apart from the oncological outcome an important aspect after bladder removal nowadays is the type of urinary diversion and its selection in various patients. Aspects addressed in modern day urinary diversion included the segment and type of reconfiguration of the gastrointestinal tract used, the anatomical location of a possible stoma, preservation of the urethra for an orthotopic diversion, the issue of an upper urinary tract protection and gender specific differences (1).

With improvement of oncological results, quality of life aspects such as continent urethral 
(orthotopic) diversion, and preservation of sexual activity became more important. In order to improve functional outcome to an acceptable level several authors have evaluated and identified the exact anatomical localization of autonomic nerves within the pelvis. Landmarks and strategies were described to preserve these structures and thereby guarantee an unaffected postoperative sexual activity in male as well as in female patients. Meticulous dissection of the bladder neck and adjacent proximal urethra with utmost preservation of both the external sphincter (rhabdosphincter) and a remnant portion of the urethral smooth musculature were of uppermost importance for postoperative continence and voiding. Furthermore, it has been suggested that in patients with an orthotopic bladder substitution preservation of autonomic nerves contributes to maintenance of continence and intact voiding function (2). A recent WHO consensus conference on bladder cancer treatment has shown that the orthotopic bladder substitution to the urethra is the most commonly used diversion in the majority of centers with emphasis on surgical treatment of bladder cancer. However, considerable regional differences exist regarding type of urinary diversion and its modifications (3).

With a clinical experience expanding over several decades now with orthotopic bladder substitution following bladder malignancy driven cystectomy the present contribution focuses on long-term data regarding oncological, functional and quality of life aspects.

\section{ONCOLOGICAL ASPECTS}

Overall 5- and 10-year recurrence-free survival in organ-confined disease in contemporary large series is $62-68 \%$ and $50-66 \%$, respectively (2-6), Table- 1 . Without treatment, about $85 \%$ of patients with muscle - invasive bladder cancer die within the first 2 years following initial diagnosis (7). Compared to other treatment strategies it has become clear over the last decades that radical cystectomy is the standard of care in high grade invasive bladder tumors, because it provides the highest survival as well as the lowest recurrence rates in these patients $(3,5,8-10)$. Several oncological and technical aspects, however, such as the necessary extent of lymphadenectomy, its diagnostic and therapeutic potential, the type of urinary diversion (e.g. ileal conduit vs. orthotopic neobladder substitution), and the impact of urethral preservation on the likelihood of urethral or local recurrences following radical cystectomy are still under discussion.

In the biggest single institution series on outcome of cystectomy in 1054 patients with a more than 10-year median survival Stein et al. reported a 5- and 10-year recurrence-free survival for patients with organ-confined, lymph node-negative tumors of $92 \%$ and $86 \%$ for P0 disease, $91 \%$ and $89 \%$ for Pis, $79 \%$ and $74 \%$ for $\mathrm{Pa}$, and $83 \%$ and $78 \%$ for $\mathrm{P} 1$ tumors, respectively. Patients with muscle invasive (P2 and P3a), lymph node-negative tumors had $89 \%$ and $87 \%$ and $78 \%$ and $76 \%$ 5-and 10 -year recurrence-free survival, respectively. Patients with nonorgan-confined (P3b, P4), lymph nodenegative tumors with or without adjuvant treatment demonstrated a significantly higher probability of recurrence compared with those with organ-confined bladder cancers $(\mathrm{P}<0.001)$. In those patients selected for surgery due to presumably localized disease 5- and 10-year recurrence-free survival for P3b tumors was $62 \%$ and $61 \%$, and for P4 tumors was $50 \%$ and $45 \%$, respectively (11).

Prostate and seminal vessel sparing cystectomy appears to be an attractive alternative to standard total cystoprostatectomy concerning sexual function and fertility. However, these advantages come at a price, i.e. a 10 to $15 \%$ higher oncological failure rate (12).

\section{LYMPH NODE INVOLVEMENT AT THE TIME OF CYSTECTOMY}

Lymphogenic metastatic spread already present at the time of surgery plays a major prognostic role but may be strongly correlated to an underlying T-stage (Table-2). $(5,11,13,14)$. Apart from lymphnodular tumor manifestation the number of positively infiltrated lymph nodes was identified as parameter of prognostic relevance.

The question whether the total number of removed nodes regardless of node involvement 
Table 1 - Largest single institution studies looking at recurrence free survival rates after cystectomy.

\begin{tabular}{lcccccc}
\hline Reference & $\begin{array}{c}\text { N of } \\
\text { Patients } \\
\text { (male + female) }\end{array}$ & $\begin{array}{c}\text { Follow-up } \\
\text { Median } \\
\text { (months) }\end{array}$ & $\begin{array}{c}\text { Recurrence Free } \\
\text { Survival }\end{array}$ & & Recurrence \\
\hline & & & 5 years & 10 years & $\begin{array}{c}\text { Local only } \\
(\%)\end{array}$ & $\begin{array}{c}\text { Distant only } \\
(\%)\end{array}$ \\
Stein (4) & 1054 & 122 & 68 & 66 & 7 & 22 \\
Madersbacher (5) & 507 & 45 & 62 & 50 & 8 & 35 \\
Hautmann (6) & 788 & 53 & 65 & 59 & 9 & 18 \\
\hline
\end{tabular}

increases the likelihood of detecting occult nodal metastases remains a controversially discussed issue. Herr (15) argued that the probability of detecting lymph node metastases might correlate with the total number of removed nodes. Others have correlated outcome to the number of involved nodes and their location $(16,17)$. Five-year disease-specific survival rates for radical cystectomy patients with lymph node metastases confined to the pelvis was reported to range between 7 and 32\%. Minimal node involvement (N1) in organ - confined bladder tumors was not an adverse prognostic situation whereas bulky nodal disease (N3) did significantly affect prognosis in these patients (18). The number of nodes involved with a cut-off ranging from 5 to 8 lymph nodes affected by metastatic disease was a significant factor for survival according to several studies $(11,13,19)$. Using the TNM criteria the 5 - year survival rate of N1 / N2 and N3 patients was $35 \%$ and $17 \%$, respectively $(15,19)$. Using a cut-off number of involved lymph nodes of 8 , Stein et al. were able to identify number of positive nodes as an independent parameter predicting clinical outcome (5).

The predictive value of the ratio between negative nodes and lymph nodes harboring metastases $(\leq 20 \% />20 \%)$ to predict the patients' clinical prognosis has been suggested (15). The 5 -year survival in patients with $\mathrm{N}+$ disease and a lymph node density of $<20 \%$ was $64 \%$, which is significantly higher than the 5-year survival of $8 \%$ for a comparable group of patients with a lymph node density of $>20 \%$. Unfortunately none of the studies addressed the issue of individual anatomical differences in the number of (normal) pelvic lymph nodes $(4,12,13,15,16)$. Thus, only a statement about "surgical" lymph node density, i.e. involved lymph nodes in relation to removed nodes, but not about the actual percentage of involved lymph nodes in individual patients is possible.

Ghoneim et al. (5) in a prospective study on 200 patients examined the value of an extended lymphadenectomy above the iliac bifurcation. There were no skipped lesions indicating that negative internal iliac and obturator nodes made a more proximal dissection unnecessary.

In summary, there is evidence that the number of lymph nodes removed, the number of positive nodes and tumor load within the lymph nodes have prognostic value in bladder cancer patients. Minimal nodal disease in organ-confined cancer may have a favorable clinical prognosis approximating that of patients with no detectable lymph node metastases

Table 2 - Incidence of histologically proven positive lymph nodes $(N+)$ at various pathological T-stages (4,16-18).

\begin{tabular}{lc}
\hline & $\mathbf{N}+\mathbf{( \% )}$ \\
\hline pTis & $1-4$ \\
pT1 & $10-13$ \\
pT2 & 15 \\
pT3a & 24 \\
pT3b & 43 \\
pT4a+b & 46 \\
\hline
\end{tabular}


in the same T-stage. Prospective randomized studies examining the recommended extension of lymphadenectomy during cystectomy have to be awaited to draw conclusions in that regard.

\section{ORTHOTOPIC URINARY DIVERSION AND TUMOR RECURRENCE}

Overall, the recurrence rate in larger series of high grade, invasive TCC, irrespective of urinary diversion ranges from $27 \%$ to $43 \%$. Eighty-six percent of all recurrences occur within 36 months following surgery, with an average interval from surgery of 12 months (4). Late recurrences at unusual sites such as the central neural system after an interval of more than 5 years have been reported especially in the setting of patients who received neoadjuvant or adjuvant chemotherapy suggesting the need for a life-long follow-up (20).

The most worrisome question in orthotopic bladder substitution is whether second primary tumors in the urothelium covered segments of the remnant urethra are frequent and might be an oncological risk for the patient. It has been demonstrated that second primary tumors of the urethra are less frequent in orthotopic neobladders than in the blind ending urethra of abdominal diversions, and are reported to occur in $5-9 \%$ (21). Studer et al. (20) reported urethral second primary tumor rate of 5\% in a series of 442 male and 40 female patients following cystectomy and orthotopic bladder substitution. Average time from surgery to recurrence was 14 months (range 3 to 158). Secondary urethrectomy was performed in 5 of the 482 patients $(1 \%)$ and a conservative treatment was attempted in 13 cases, 2 of them requiring urethrectomy thereafter. For the whole cohort of neobladder patients suffering from urethral tumor recurrence, the median overall survival decreased to 38 months and 14 patients $(2.9 \%)$ died from systemic tumor progression.

In a retrospective series of 768 male patients by Stein et al. (21) overall second primary tumor rate was $6 \%$, irrespective of urinary diversion. In a multivariate statistical analysis, prostatic involvement by the primary tumor as well as cutaneous urinary diversion were independently associated with an increased risk for the development of second primary tumors. The calculated risk of second primary tumors was 5 and $9 \%$ for patients with an orthotopic and cutaneous urinary diversion, respectively. A difference for second primary tumors depending on initial prostatic tumor involvement was apparent for both superficial (12 vs. $5 \%)$ and invasive transitional cell carcinoma (TCC) (18 vs. 5\%). A protective effect of urine in contact to the urethra, a reduction of bacterial cancerogenesis or a selection bias could be reasons for the more favorable urethral tumor rate in neobladder patients.

The hypothesis that female patients harbor an increased risk for the development of second primary tumors and should therefore have a mandatory urethrectomy as an integral part of cystectomy has been abandoned more than a decade ago. The incidence of second primary tumors in females subjected to orthotopic neobladder substitution is comparable to male series and predictive (22-24). In 841 female patients followed for more than 20 years, the urethral tumor rate was $2 \%$. All patients with urethral tumors had primary tumors located at the bladder neck and/or the trigone in the.

In a series reported by Hautmann et al. (25) of 643 male and female neobladder patients, local pelvic recurrences and urethral recurrences were observed in $10 \%$ and $2 \%$ of cases, respectively. Voiding function was compromised in $2 \%$ of cases. Even in these $2 \%$ of the patients where outlet obstruction occurred it could be treated with intermittent self catheterization, chemotherapy, radiotherapy and/or resection.

Entero-enteral and entero-reservoir fistulas mainly due to preoperative radiotherapy, use of stapler devices, or local tumor recurrence have been described to affect up to $2 \%$ of patients $(20,26)$. Nontumor related and possibly some of the tumor related entero-reservoir fistulas may be prevented with the use of omentum or omental flaps at the time of initial surgery (27).

In contemporary series, second primary tumors of the upper tract in patients with urinary diversion due to TCC occur in $2.4-17 \%$ of patients after an average time interval between 8 and 69 months with the biggest series of 1069 patients reporting an incidence of $2.5 \%$ and a median survival of 1.7 years 
(range 0.2-8.8) (28). Upper tract recurrences more than 10 years after cystectomy have been observed (29).

In conclusion, tumor recurrence both in the urethra and in the upper urinary tract following orthotopic bladder replacement is acceptably low and should therefore per se not influence a decision towards a heterotopic diversion.

\section{CONTINENCE AND URINARY RETENTION IN MALE PATIENTS}

In using detubularized intestinal segments for construction of a low pressure reservoir aiming at a filling capacity of approximately $400-500 \mathrm{~mL}$, continence is mainly achieved by utmost preservation of the urethral sphincter and its innervation. The rhabdosphincter in the male is not a circular structure limited to the prostatic apex but extends cranially along the ventral prostatic surface all the way to the bladder neck (30). By making every effort to carefully dissect this ventral portion off the prostate a larger amount of striated muscle cells can be preserved. Autonomic nerve preservation has shown to further improve continence by preserving afferent sensory nerves to the membranous urethra (31). Day - time continence defined as $0-1$ pads per day was achieved in $88-95 \%$ of male and female patients after a minimum follow-up of one year in recent series (32-34). Night-time continence - depending on definition and management of the patients is usually lower, ranging from 66 to $93 \%(5,20,26,35)$. Over time, continence seems to decrease slightly, possibly to a decreased muscle tone and number of muscle cells the external rhabdosphincter related to changes with age $(5,20,36,37)$. Nerve sparing surgical approaches as outlined above seem to improve the continence following orthotopic neobladder substitution both in male and female patients (36,38). A significantly longer functional urethral length and a higher maximal urethral pressure have been observed in patients undergoing nerve preservation in comparison to a non nerve-sparing control group (39). In neobladder patients preservation of autonomic innervation and age are the predominant factors affecting functional outcome (31).
In a large series with a follow-up of up to two decades Studer et al. observed residual urine volumes of more than $100 \mathrm{~mL}$ in $22 \%$ of all male and female neobladder patients (20). Urethral anastomotic strictures occurred in $3.7 \%$, an occluding protrusion of the ileal mucosa over the neobladder outlet (termed ileal valve (27)) in 7\%, and obstruction due to subtotal resection of the prostate in $1.7 \%$ of all patients.

The majority of the patients could be treated endoscopically. Two percent of the patients remained on a permanent catheter and $2.9 \%$ were instructed to perform intermittent self-catheterization (20). Hautmann et al. reported transient or permanent retention in $4 \%$ of male patients (25), Abol-Enein found an infravesical obstruction in $3 \%$ in a series of 344 evaluated male patients with a mean follow up of 38 months (40).

\section{ONCOLOGICAL AND FUNCTIONAL OUTCOME IN FEMALE PATIENTS}

Long term results in a growing number of female patients with orthotopic bladder substitution have verified that removing the bladder neck and a small portion of adjacent urethra but leaving a large portion of the urethra will not compromise oncological outcome (41).

In altogether 230 female bladder cancer patients with an orthotopic bladder substitution second primary tumors were observed in 1.4 to $4.3 \%$ of women after a mean follow-up of 36 to 50 months $(42,43)$.

Diurnal and nocturnal continence rates ranging from $82-95 \%$ and $72-86 \%$ respectively $(32,44,45)$ were comparable to male patients. This continence rate despite the shorter remnant urethra used as neobladder outlet compared to male patients is remarkable and in some series may be partially the result of preservation of afferent and efferent autonomic nerves supplying urethral smooth musculature.

Removal of the bladder neck and an adjacent short segment of urethra is not only beneficial from an oncological standpoint but also improves outcome regarding volitional voiding (27). 
The increased rates of urinary retention seen in female compared to male neobladder patients may be manifold. Leaving a too long segment of urethra might result in too much resistance for a low pressure intestinal reservoir. In an early series of women undergoing cystectomy without removing the entire bladder neck and subsequent orthotopic bladder substitution a majority of patients went into urinary retention (46). Preservation of autonomic nerves supplying the remnant urethra during cystectomy will not only reduce apoptosis of smooth muscle cells (30) but might also preserve the shortening and widening of the urethra thus facilitating volitional voiding.

The wider female pelvis and a shorter distance between mesenteric origin and urethra may be responsible for the phenomenon of the "ileal valve" mechanically obstructing the neobladder outlet predominantly in women (27). Whether a reduced angulation between neobladder floor and urethra leads to an increased retention rate and whether a correction or prevention with omentum, position sutures or vaginal suspension may play a role is still a matter of debate. Contemporary larger series report urinary retention and intermittent self-catheterization rates in 15 to $25 \%$ $(21,32,47)$ where the bladder neck was removed and autonomic nerve preservation was attempted, and up to $50 \%$ where no explicit nerve preservation was done (25).

\section{INTESTINAL RESERVOIR AND URETEROINTESTINAL CONNECTION}

A recently published WHO consensus report summarizes a contemporary frequency distribution of various forms and techniques of urinary diversions in $>7000$ patients with cystectomy. Forty-seven percent of male and female patients in the participating institutions received an orthotopic neobladder which was thus the most frequently used type of diversion (3).

The preferred type of bowel in the largest recent series dealing with orthotopic urinary diversion is terminal ileum $(4,25)$. Arguments in favor of colonic segments such as the reduced length of bowel necessary to achieve an adequate volume, the use of the ileocecal valve as an antireflux mechanism, and a reduced rate of long term urinary retention have been proposed $(48,49)$. However, less metabolic consequences and dysentery, easier surgical technique, better nocturnal continence rates, and a better functional protection of the upper urinary tract may have lead to the wide adoption of the ileal neobladder $(2,50)$.

Ureteroilial stenosis was reported to occur in $2.7 \%$ of patients with an afferent tubular segment (20) and in $3.8 \%$ of patients with a serosa - lined extramural tunnel technique (40). Anatomical considerations leading to a meticulous vascularization sparing surgical technique (51) are important for a good outcome (52). Preference should be given to those techniques which will enable transurethral access to the upper tract in case of tumor recurrence, lithiasis and other endoscopically correctable problems in the upper urinary tract (52).

Long-term protection of renal function in bladder substitution could be demonstrated in the vast majority of patients. Anastomosing the ureters onto an afferent tubular segment rising serum creatinine levels were observed after a 5-year follow-up in 3.8\% of cases (20). With the serosa - lined extramural tunnel technique renal function was preserved in $96.2 \%$ of patients after a mean follow-up of 38 months (40).

\section{QUALITY OF LIFE}

Heningssohn et al. (53) evaluated the quality of life in a cohort of patients subjected to radical cystectomy and orthotopic bladder substitution. The subjective global quality of life of 101 consecutive, recurrence - free bladder patients were comparable to a matched non-operated control group. Hobisch et al. (54) found that quality of life was preserved to a higher degree with an orthotopic neobladder compared to an ileal conduit urinary diversion in 102 male and female patients with a mean follow-up of 37 months. Other studies comparing different types of urinary diversion (incontinent vs. continent vs. orthotopic diversion) were unable to confirm a superior quality of one type of reconstruction over the others with regard to quality of life (55-57). An important proposed reason for this is that patients are subjected preoperatively to method-to-patient matching, and thus are prepared for disadvantages associated with different methods (3). 
Distress in patients after cystectomy and continent urinary diversion in general was due to a compromised sexual function, urinary problems and bowel dysfunction (53).

\section{SEXUAL ACTIVITY}

Similar to continence and micturition potency and sexual activity are strongly correlated with autonomic nerve preservation and potency. Schoenberg et al. reported a correlation between age and potency in nerve sparing cystectomy in a 10-16 year experience with 101 male patients reporting a potency rate of $62 \%$ in men 49 years and younger, which decreased to $20 \%$ in men $70-79$ years old (58). This was confirmed by several other studies. In a series from Berne by Kessler et al. comprising of 331 men (31) after a mean follow-up of 24 months recovery of erectile function was significantly more frequent in younger patients $(<65$ years) and those with preserved autonomic nerves. In a subsequent larger group of patients the same group reported an overall potency rate (including those with medical assistance) of $38 \%$ (20). In a smaller study from Japan $51 \%$ of men age 40 to 59 years were able to have sexual intercourse (59).

With regards to female cystectomy various studies showed a deterioration of sexual function after radical cystectomy $(60,61)$ with only half of the patients reporting to have successful sexual intercourse. The most common complaints of the women still practicing sexual intercourse were inability to receive orgasms, decreased vaginal lubrication, decreased sexual desire and dyspareunia (61). A single study compared sexual function in female patients after nerve sparing cystectomy and non nerve-sparing approaches (62). In this small study, the patients in the nerve sparing group showed only a minimal decline in Female Sexual Function Index, whereas the women in the non-nerve sparing group showed a significant decline.

\section{METABOLIC CHANGES}

The utilization of bowel for urinary diversion interferes with the physiological renal acid and salt regulation. Meticulous monitoring, careful electrolyte balance as well as sufficient hydration within the first postoperative time help to avoid dehydration and electrolyte depletion (63). Osteoporosis and osteomalacia might theoretically develop from a persistent hypokalemic, hyperchloremic acidosis. A transient acidosis developing postoperatively is common and should be controlled by usually oral intake of sodium bicarbonate. Within 4 years of the operation, reabsorption of metabolic substances of intestinal reservoirs and thereby the extent of metabolic problems associated with neobladder substitution significantly decreased (64).

In a recent investigation by Studer et al. abnormal bone density could not be observed in well-monitored patients for whom a follow-up of at least 10 years was available. In larger series including 314 patients where terminal ileum was used to substitute the urinary tract decreased Vitamin B12 levels required a substitution in 5\% of cases (20). It is therefore suggested that surgical exclusion of the terminal ileum necessitates regular checking and at times substitution of Vitamin B12 after a follow-up of more than 5 years.

\section{ELDERLY PATIENTS}

In those elderly patients, defined as patients older than 75 to 80 years, which had been selected for surgery mortality and complication rates were similar compared to younger patients. Thus, chronological age is not a contraindication for radical cystectomy with curative intent, provided patients are selected carefully, and a preoperative risk assessment is done combined with a non-oncological life expectancy evaluation which should exceed 2 years (65).

Clark et al. (66) in a retrospective review of 1054 patients with cystectomy for curative intent and a median follow-up of 10.2 years found a similar mortality as well as diversion related complication rate in age groups less than $60(\mathrm{n}=309), 60-69(\mathrm{n}$ $=381), 70-79(\mathrm{n}=314)$ and 80 years or older. The operative mortality rates were $1 \%, 3 \%, 4 \%$ and $0 \%$ in each group. A lower proportion of patients older than 80 years underwent an orthotopic diversion. Three 
and 5-year overall survival rates of $60 \%$ and $53 \%$ in patients aged 70 or older compared to $68 \%$ and $63 \%$, respectively, in patients younger than 70 years were seen in this large retrospective study (67).

\section{CONCLUSION}

After more than 3 decades of clinical experience, orthotopic bladder substitution subsequent to radical cystectomy has stood the test of time by providing adequate long-term survival and low local recurrence rates. Orthotopic bladder substitution does not compromise oncological outcome, yields excellent functional results, is cost effective compared to other types of urinary diversion, may improve quality of life and should therefore be the diversion of choice both in men and women. Chronological age is generally not a contraindication for cystectomy, but for orthotopic urinary diversion, a careful patient selection considering tumor extent, patient motivation, preoperative sphincter function, other local and systemic adverse confounding factors and overall life expectancy must be taken into account. Minimally invasive techniques are promising concepts for the future, awaiting confirmation in larger patient cohorts.

\section{ACKNOWLEDGMENT}

The authors dedicate this paper to John P. Stein, M.D. who unexpectedly died. He has extensively contributed to the contemporary knowledge on this subject.

\section{CONFLICT OF INTEREST}

None declared.

\section{REFERENCES}

1. Hendren WH: Historical perspective of the use of bowel in urology. Urol Clin North Am. 1997; 24: 70313.

2. Stenzl A, Cowan NC, De Santis M, Jakse G, Kuczyk MA, Merseburger AS, Ribal MJ, Sherif A, Witjes JA:
The updated EAD guidelines on muscle-invasive and metastatic bladder cancer. Eur Urol 2009; 55: 815525.

3. Hautmann RE, Abol-Enein H, Hafez K, Haro I, Mansson W, Mills RD, et al.: For the WHO, Consensus Conference on Bladder Cancer "Urinary diversion" Urology. 2007; 69 (1 Suppl): 17-49.

4. Stein JP, Lieskovsky G, Cote R, Groshen S, Feng AC, Boyd S, et al.: Radical cystectomy in the treatment of invasive bladder cancer: long-term results in 1,054 patients. J Clin Oncol. 2001; 19: 666-75.

5. Madersbacher S, Hochreiter W, Burkhard F, Thalmann GN, Danuser H, Markwalder R, et al.: Radical cystectomy for bladder cancer today--a homogeneous series without neoadjuvant therapy. J Clin Oncol. 2003; 21: 690-6.

6. Hautmann RE, Gschwend JE, de Petriconi RC, Kron M, Volkmer BG: Cystectomy for transitional cell carcinoma of the bladder: results of a surgery only series in the neobladder era. J Urol. 2006; 176: 486-92; discussion 491-2.

7. Prout GR, Marshall VF: The prognosis with untreated bladder tumors. Cancer. 1956; 9: 551-8.

8. Stein JP: Indications for early cystectomy. Urology. 2003; 62: 591-5.

9. Montie JE: Against bladder sparing: surgery. J Urol. 1999; 162: 452-5; discussion 455-7.

10. Shipley WU, Kaufman DS, Heney NM, Althausen AF, Zietman AL: An update of selective bladder preservation by combined modality therapy for invasive bladder cancer. Eur Urol. 1998; 33(Suppl 4) :32-4.

11. Stein JP, Cai J, Groshen S, Skinner DG: Risk factors for patients with pelvic lymph node metastases following radical cystectomy with en bloc pelvic lymphadenectomy: concept of lymph node density. J Urol. 2003; 170: $35-41$.

12. Hautmann RE, Stein JP: Neobladder with prostatic capsule and seminal-sparing cystectomy for bladder cancer: a step in the wrong direction. Urol Clin North Am. 2005; 32: 177-85.

13. Lerner SP, Skinner E, Skinner DG: Radical cystectomy in regionally advanced bladder cancer. Urol Clin North Am. 1992; 19: 713-23.

14. Vazina A, Dugi D, Shariat SF, Evans J, Link R, Lerner SP: Stage specific lymph node metastasis mapping in radical cystectomy specimens. J Urol. 2004; 171: 1830-4.

15. Herr HW: Superiority of ratio based lymph node staging for bladder cancer. J Urol. 2003; 169: 9435 . 
16. Abdel-Latif M, Abol-Enein H, El-Baz M, Ghoneim MA: Nodal involvement in bladder cancer cases treated with radical cystectomy: incidence and prognosis. J Urol. 2004; 172: 85-9.

17. Leissner J, Hohenfellner R, Thüroff JW, Wolf HK: Lymphadenectomy in patients with transitional cell carcinoma of the urinary bladder; significance for staging and prognosis. BJU Int. 2000; 85: 81723.

18. Vieweg J, Gschwend JE, Herr HW, Fair WR: Pelvic lymph node dissection can be curative in patients with node positive bladder cancer. J Urol. 1999; 161: 44954.

19. Mills RD, Turner WH, Fleischmann A, Markwalder R, Thalmann GN, Studer UE: Pelvic lymph node metastases from bladder cancer: outcome in 83 patients after radical cystectomy and pelvic lymphadenectomy. J Urol. 2001; 166: 19-23.

20. Studer UE, Burkhard FC, Schumacher M, Kessler TM, Thoeny H, Fleischmann A, et al.: Twenty years experience with an ileal orthotopic low pressure bladder substitute--lessons to be learned. J Urol. 2006; 176: 161-6.

21. Stein JP, Clark P, Miranda G, Cai J, Groshen S, Skinner DG: Urethral tumor recurrence following cystectomy and urinary diversion: clinical and pathological characteristics in 768 male patients. J Urol. 2005; 173: 1163-8.

22. Stein JP, Esrig D, Freeman JA, Grossfeld GD, Ginsberg DA, Cote RJ, et al.: Prospective pathologic analysis of female cystectomy specimens: risk factors for orthotopic diversion in women. Urology. 1998; 51: 951-5.

23. Stenzl A, Draxl H, Posch B, Colleselli K, Falk M, Bartsch G: The risk of urethral tumors in female bladder cancer: can the urethra be used for orthotopic reconstruction of the lower urinary tract? J Urol. 1995; 153: 950-5.

24. Coloby PJ, Kakizoe T, Tobisu K, Sakamoto M: Urethral involvement in female bladder cancer patients: mapping of 47 consecutive cysto-urethrectomy specimens. J Urol. 1994; 152: 1438-42.

25. Hautmann RE, Volkmer BG, Schumacher MC, Gschwend JE, Studer UE: Long-term results of standard procedures in urology: the ileal neobladder. World J Urol. 2006; 24: 305-14.

26. Hautmann RE, de Petriconi R, Gottfried HW, Kleinschmidt K, Mattes R, Paiss T: The ileal neobladder: complications and functional results in 363 patients after 11 years of followup. J Urol. 1999; 161: 422-7; discussion 427-8
27. Stenzl A, Colleselli K, Bartsch G: Update of urethrasparing approaches in cystectomy in women. World $\mathrm{J}$ Urol. 1997; 15: 134-8.

28. Sanderson KM, Cai J, Miranda G, Skinner DG, Stein JP: Upper tract urothelial recurrence following radical cystectomy for transitional cell carcinoma of the bladder: an analysis of 1,069 patients with 10-year followup. J Urol. 2007; 177: 2088-94.

29. Stenzl A, Bartsch G, Rogatsch H: The remnant urothelium after reconstructive bladder surgery. Eur Urol. 2002; 41: 124-31

30. Strasser H, Ninkovic M, Hess M, Bartsch G, Stenzl A: Anatomic and functional studies of the male and female urethral sphincter. World J Urol. 2000; 18: 324-9.

31. Kessler TM, Burkhard FC, Perimenis P, Danuser H, Thalmann GN, Hochreiter WW, et al.: Attempted nerve sparing surgery and age have a significant effect on urinary continence and erectile function after radical cystoprostatectomy and ileal orthotopic bladder substitution. J Urol. 2004; 172: 1323-7.

32. Stenzl A, Jarolim L, Coloby P, Golia S, Bartsch G, Babjuk M, et al.: Urethra-sparing cystectomy and orthotopic urinary diversion in women with malignant pelvic tumors. Cancer. 2001; 92: 1864-71.

33. Gburek BM, Lieber MM, Blute ML: Comparison of studer ileal neobladder and ileal conduit urinary diversion with respect to perioperative outcome and late complications. J Urol. 1998; 160: 721-3.

34. Steven K, Poulsen AL: The orthotopic Kock ileal neobladder: functional results, urodynamic features, complications and survival in 166 men. J Urol. 2000; 164: 288-95.

35. Ghoneim MA, Shaaban AA, Mahran MR, Kock NG: Further experience with the urethral Kock pouch. J Urol. 1992; 147: 361-5.

36. Strasser H, Marksteiner R, Margreiter E, Pinggera GM, Mitterberger M, Frauscher F, et al.: Autologous myoblasts and fibroblasts versus collagen for treatment of stress urinary incontinence in women: a randomised controlled trial. Lancet. 2007; 369: 2179-86. Erratum in: Lancet. 2008; 371: 474. Retraction in: Kleinert S, Horton R. Lancet. 2008; 372: 789-90.

37. Strasser H, Tiefenthaler M, Steinlechner M, Bartsch $\mathrm{G}$, Konwalinka G: Urinary incontinence in the elderly and age-dependent apoptosis of rhabdosphincter cells. Lancet. 1999; 354: 918-9.

38. Stenzl A, Colleselli K, Poisel S, Feichtinger H, Pontasch H, Bartsch G: Rationale and technique of nerve sparing radical cystectomy before an orthotopic neobladder procedure in women. J Urol. 1995; 154: 2044-9. 
39. Turner WH, Danuser H, Moehrle K, Studer UE: The effect of nerve sparing cystectomy technique on postoperative continence after orthotopic bladder substitution. J Urol. 1997; 158: 2118-22.

40. Abol-Enein H, Ghoneim MA: Functional results of orthotopic ileal neobladder with serous-lined extramural ureteral reimplantation: experience with 450 patients. J Urol. 2001; 165: 1427-32.

41. Wu SD, Simma-Chang V, Stein JP: Pathologic guidelines for orthotopic urinary diversion in women with bladder cancer: a review of the literature. Rev Urol. 2006; 8: 54-60.

42. Ali-el-Dein B, Abdel-Latif M, Ashamallah A, AbdelRahim M, Ghoneim M: Local urethral recurrence after radical cystectomy and orthotopic bladder substitution in women: a prospective study. J Urol. 2004; 171: 275-8.

43. Akkad T, Gozzi C, Deibl M, Müller T, Pelzer AE, Pinggera GM, et al.: Tumor recurrence in the remnant urothelium of females undergoing radical cystectomy for transitional cell carcinoma of the bladder: longterm results from a single center. J Urol. 2006; 175: 1268-71; discussion 1271.

44. Ali-El-Dein B, Gomha M, Ghoneim MA: Critical evaluation of the problem of chronic urinary retention after orthotopic bladder substitution in women. J Urol. 2002; 168: 587-92.

45. Stein JP, Stenzl A, Grossfeld GD, Freeman JA, Esrig D, Boyd SD, et al.: The use of orthotopic neobladders in women undergoing cystectomy for pelvic malignancy. World J Urol. 1996; 14: 9-14.

46. Hautmann RE: The ileal neobladder to the female urethra. Urol Clin North Am. 1997; 24: 827-35.

47. Bhatta Dhar N, Kessler TM, Mills RD, Burkhard F, Studer UE: Nerve-sparing radical cystectomy and orthotopic bladder replacement in female patients. Eur Urol. 2007; 52: 1006-14.

48. Thüroff JW, Franzaring L, Gillitzer R, Wöhr M, Melchior S: Simplified orthotopic ileocaecal pouch (Mainz pouch) for bladder substitution. BJU Int. 2005; 96: 443-65.

49. Okada H, Yamanaka N, Oh-Oka H, Gotoh A, Nakamura I, Hara I, et al.: Construction and voiding functions of three types of orthotopic neobladders using colonic segments: the Kobe University experience. Int J Urol. 1998; 5: 22-9.

50. Schrier BP, Laguna MP, van der Pal F, Isorna S, Witjes JA: Comparison of orthotopic sigmoid and ileal neobladders: continence and urodynamic parameters. Eur Urol. 2005; 47: 679-85.

51. Kouba E, Sands M, Lentz A, Wallen E, Pruthi RS: A comparison of the Bricker versus Wallace ureteroileal anastomosis in patients undergoing urinary diversion for bladder cancer. J Urol. 2007; 178: 945-8; discussion 948-9.

52. Stenzl A, Hobisch A, Strasser H, Bartsch G: Ureteroileal anastomosis in orthotopic urinary diversion: how much or how little is necessary? Tech Urol. 2001; 7: 188-95.

53. Henningsohn L, Steven K, Kallestrup EB, Steineck G: Distressful symptoms and well-being after radical cystectomy and orthotopic bladder substitution compared with a matched control population. J Urol. 2002; 168: 168-74; discussion 174-5.

54. Hobisch A, Tosun K, Kinzl J, Kemmler G, Bartsch G, Höltl L, et al.: Quality of life after cystectomy and orthotopic neobladder versus ileal conduit urinary diversion. World J Urol. 2000; 18: 338-44.

55. Hart S, Skinner EC, Meyerowitz BE, Boyd S, Lieskovsky G, Skinner DG: Quality of life after radical cystectomy for bladder cancer in patients with an ileal conduit, cutaneous or urethral kock pouch. J Urol. 1999; 162: 77-81.

56. Allareddy V, Kennedy J, West MM, Konety BR: Quality of life in long-term survivors of bladder cancer. Cancer. 2006; 106: 2355-62.

57. Gerharz EW, Månsson A, Hunt S, Skinner EC, Månsson W: Quality of life after cystectomy and urinary diversion: an evidence based analysis. J Urol. 2005; 174: 1729-36.

58. Schoenberg MP, Walsh PC, Breazeale DR, Marshall FF, Mostwin JL, Brendler CB: Local recurrence and survival following nerve sparing radical cystoprostatectomy for bladder cancer: 10-year followup. J Urol. 1996; 155: 490-4.

59. Miyao N, Adachi H, Sato Y, Horita H, Takahashi A, Masumori N, et al.: Recovery of sexual function after nerve-sparing radical prostatectomy or cystectomy. Int J Urol. 2001; 8: 158-64.

60. Volkmer BG, Gschwend JE, Herkommer K, Simon J, Küfer R, Hautmann RE: Cystectomy and orthotopic ileal neobladder: the impact on female sexuality. J Urol. 2004; 172: 2353-7.

61. Zippe CD, Raina R, Shah AD, Massanyi EZ, Agarwal A, Ulchaker J, et al.: Female sexual dysfunction after radical cystectomy: a new outcome measure. Urology. 2004; 63: 1153-7.

62. Nandipati KC, Bhat A, Zippe CD: Neurovascular preservation in female orthotopic radical cystectomy significantly improves sexual function. Urology. 2006; 67: 185-6.

63. Mills RD, Studer UE: Metabolic consequences of continent urinary diversion. J Urol. 1999; 161: 1057-66. 


\section{Radical Cystectomy with Neobladder for Bladder Cancer}

64. Hautmann RE: Urinary diversion: ileal conduit to neobladder. J Urol. 2003; 169: 834-42.

65. Gschwend JE, Hautmann RE, Volkmer BG: Radical cystectomy and urinary diversion in elderly patients with increased comorbidity. Urologe A. 2004; 43: 930-4.

66. Clark PE, Stein JP, Groshen SG, Cai J, Miranda G, Lieskovsky G, et al.: Radical cystectomy in the elderly: comparison of clincal outcomes between younger and older patients. Cancer. 2005; 104: 36-43.

67. Figueroa AJ, Stein JP, Dickinson M, Skinner EC, Thangathurai D, Mikhail MS, et al.: Radical cystectomy for elderly patients with bladder carcinoma: an updated experience with 404 patients. Cancer. 1998; 83: $141-7$

\section{Correspondence address:}

Dr. Arnulf Stenzl

Department of Urology

University of Tuebingen

Hoppe-Seyler-Str. 3

Tuebingen 72076, Germany

Fax: + 4970 7129-5092

E-mail: urologie@med.uni-tuebingen.de 